\title{
Conformational Analysis and Electronic Properties of 2-Cyano-3-(thiophen-2-yl)acrylic Acid in Sensitizers for Dye-sensitized Solar Cells: A Theoretical Study
}

\author{
Mannix P. Balanay, Se-Mi Kim, Mi Jung Lee, Sang Hee Lee, and Dong Hee Kim \\ Deparment of Chemistry, Kumsan National Lniversity, Gunsan 573-701, Korea. E-mail: dhkimakinsan.acker \\ Recened Mav 1+. 2009. Accepted Alugust 4,2009
}

\begin{abstract}
The confonmational and electronic properties of 2-cyano-3-(thiophen-2-yl)acry lic acid (TCA) in analogues used as sensitizers in dye-sensitized solar cells was examined using density functional theory (DFT) and natural bond orbital analysis methods. A relaxed potential energy surface scan was performed on NKX-2677 by rotating the C-C bond between the thiophene and cyanoacry lic acid which yielded activation energy barriers of about $13 \mathrm{kcal} / \mathrm{mol}$ for both $\mathrm{E}$ and $\mathrm{Z}$ configurations. The most stable conformation of all the analogues was $\mathrm{E}-180$ except for NKX-2587 which has an electrostatic repulsion between the oxygen of the coumarin and the nitrogen of the cyanoacrylic acid. The increase in the electron delocalization between the thiophene and cyanoacrylic acid influences the stability for most of the analogues. But for NKX-2600, even though there was a greater deviation from the planarity of TCA, the stability was mainly due to the presence of a weak hydrogen bond between the hydrogen of the methyl group of the anine located in the donor moiety and the nitrogen of the cyanoacry lic acid. The vertical excitation energies of the analogues containing TCA were calculated by time-dependent DFT method. There vere slight differences in its vertical excitation energies but the oscillator strengths vary significantly especially in the case of NKX-2600.
\end{abstract}

Key Words: Conformation. Thiophene. Cyanoacrylic acid. DFT. DSSC

\section{Introduction}

Thiophene and its oligomers are among the most frequently used $\pi$-spacer in organic dyes having a donor- $(\pi$-conjugated bridge)-acceptor (D- $\pi$-A) sy'stem in dye-sensitized solar cells (DSSCs) due to its high structural stability. ease of structural modification and controllable electrochemical behavior. ${ }^{1 \cdot{ }^{12}}$ The ligh structural stability exhibited by thiophenes is due to their rigid structures that limit photoisomerization processes commonly observed in polyenes and polyynes. Furthermore. thiophene has a lower aromatic delocalization energy with a high nonlinear optical property than benzene since it has a greater tendency to be co-planar with the other thiophene groups. ${ }^{13}$ The lowering of aromatic delocalization energy increases the mixing of the ground state and charge-transfer state leading to increased polarizability and hyperpolarizability. ${ }^{14}$ Thiophene can also be easily modified to enhance stability and photochemical properties such as incorporating an arylamine donor giving a more delocalized positive charge that could retard back electron transfer to the oxidized dye $e^{4}$ or attaching bulky alkyl substituents to increase hydrophobicity of the dye. These structural changes can improve the packing of the dye on the surface and act as a barrier preventing hydrophilic $\mathrm{I}_{3}{ }^{-}$ions from approaching $\mathrm{TiO}_{2}$, thereby retarding electron leakage to the redos electrolyte. ${ }^{11.12}$

It was shown from previous experiments ${ }^{15.16}$ that the electronic coupling between the dye and $\mathrm{TiO}_{2}$ surface through the binding or acceptor group has an important role in the efficiency of light harvesting. The most viable candidate that can efficiently act as a linker moiety is cy anoacrylic acid. since carboxylic acid binds strongly to the $\mathrm{TiO}_{2}$ surface through a bidentate bridging mode which is not easily removed by rinsing and the presence of the cyano group enhances the electron-withdrawing nature of linker moiety which can shift the oxidation potentials posi- tively but does not take part in the adsorption process. ${ }^{1 \leqslant 1}$ :

There is a significant interest in the design and optimization of the sensitizers containing 2-cyano-3-(thiophen-2-yl)acrylic acid (TCA) for use in DSSCs. however a detailed understanding of the structure-property relationships for such system is still lacking. With the use of theoretical calculations - which is an indispensable tool in rationalizing the experimentally observed photochemical properties and designing sensitizers to be used in DSSCs - structure-property relationships can be studied through detailed description of orbitals. including spatial characteristics. nodal pattens. and individual atom contributions. Thus, the knowledge of the conformer of the lowest energy is important because electronic properties depend on detailed molecular structure

In view of the conflicting conformation of TCA presented in various papers, ${ }^{-111}$ we carried out a conformational study of analogues containing $\mathrm{TCA}^{1.3}$ (Fig. 1) to determine the lowest energy conformation of TCA and its effect on its electronic properties using density functional theory and natural bond orbital (NBO) analysis methods. NBO analysis was carried out to understand the orbital interaction that determines the conformational preference of TCA in analogues used as sensitizers for DSSCs.

\section{Computational Method}

All calculations were performed with the Gaussian 03 (G03) package ${ }^{18}$ enploying density functional theory with the hybrid B3LYP ${ }^{19.2(1}$ fiunctional at 6-3 IG(d) basis set. A relaved potential energy surface (PES) scan for dihedral angle. $\theta(\mathrm{C} 3-\mathrm{C} 4-\mathrm{C} 6-\mathrm{C} 7)$ (Fig. 2), was carried out at $15^{\circ}$ interval in the range of $0 \sim 180^{\circ}$ for the $E$ and $Z$ configuration of NKX-2677. To obtain the ground state geometries of each analogue, two most stable 
<smiles></smiles>

NKX-2677<smiles>CN(C)c1ccc(C(=Cc2ccc(C=C(C#N)C(=O)O)s2)c2ccc(N(C)C)cc2)cc1</smiles>

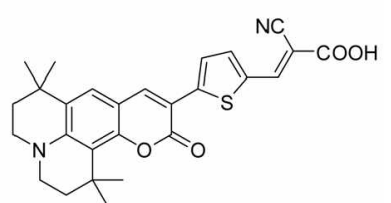

NKX-2587

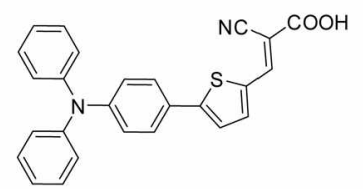

L1

Figure 1. Structures of sensitizers containing 2-cvano- $\hat{i}$-(thiophen- $2-\mathrm{vl}$ ) acrolic acid (ICA).

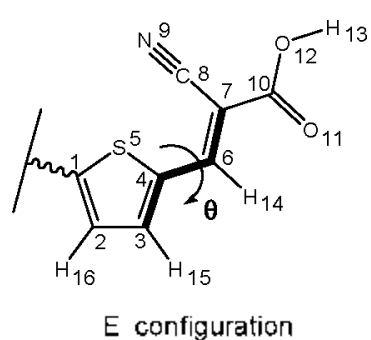

Figure 2. Numbering soldeme of the li and \% contiguration of the TCA portion of NKX-2677, o is the dihedral angle about C3-C4- C6-C7.

conformers of NKX-2677. NKX-2587. NKX-2600. and LI from the PES scan were calculated in vacuo without any syminetry constraints at the same level of theory: They are named according to the researchers who synthesized the dyes. ${ }^{1-3}$ Frequency calculations with no scaling were performed to ensure that all optimized molecular structures were minuma and to determine the zero-point energy corrections. Natural bond orbital analysis was perforned with $\mathrm{NBO}$ version $3.1^{21}$ incorporated in the $\mathrm{G} 03$ package using the ground state geometrics. NBO analy sis provides a quantitative description of interactions ilat dictale the conformational features of the analogues. Time-dependent density functional theory at TD-B3LYP/6-3lG(d) using the ground state geometries was used to calculate vertical excitation cnergics of the analogues. QMForge ${ }^{21}$ was used to calculate molecular orbital contribution from groups of atoms.

\section{Results and Discussion}

The ground state potential energy surface scan of the $E$ and $Z$ configuration of 2-cyano-3-(thiophen-2-yl)acrylic acid of NKX-2677 was calculated using B3LYP/6-3 IG(d) as a function of the dithedral angle. $\theta$ (C3-C4-C6-C7). by rotating $\mathrm{C} 4-\mathrm{C} 6$ bond between the thiophene and cyanoacrylic acid (Fig. 2). Rotations around the $\mathrm{C} 4-\mathrm{C} 6$ bond yielded energy barriers of about $13 \mathrm{kcal} / \mathrm{mol}$ for both configurations (Fig. 3a). The rotation resulted in the reduction of the overlap between the $p_{2}$ orbitals on these carbons. This in tum weakens the $\mathrm{C} 4-\mathrm{C} 6 \pi$-bond cla-

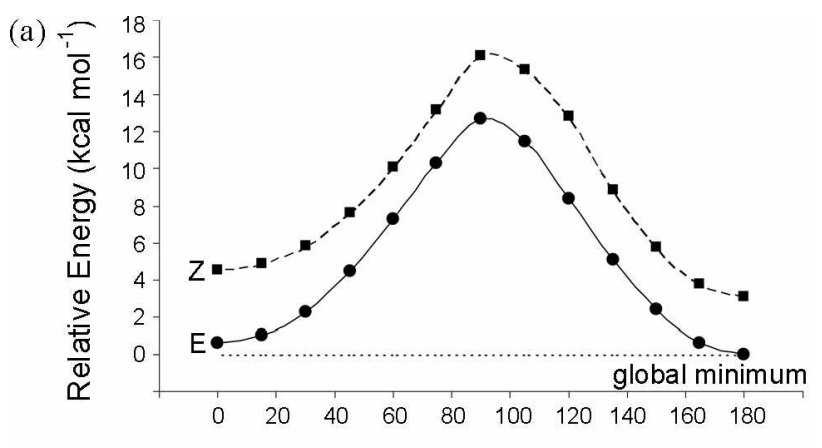

Dihedral Angle, $\theta$ (C3-C4-C6-C7) (degrees)

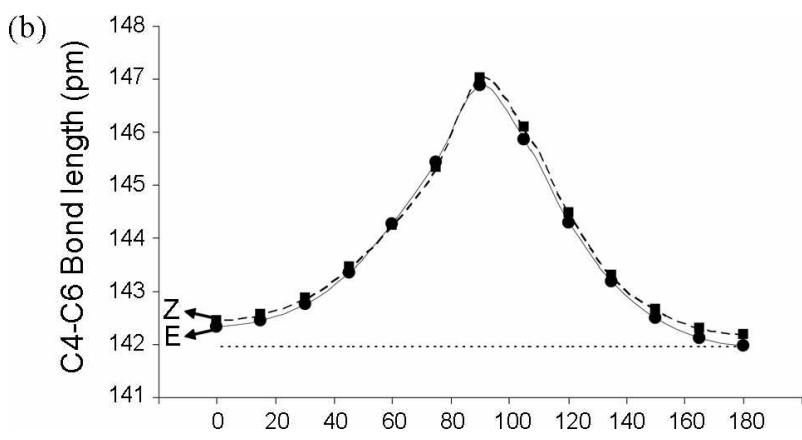

Dihedral Angle, $\theta$ (C3-C4-C6-C7) (degrees)

Figure 3. (a) Potential encrgy sufface scan and (b) C4-C6 bond lengths as a tunction of the dihedral angle, $\theta(\mathrm{C} 3-\mathrm{C} 4-\mathrm{C} 6-\mathrm{C} 7)$, tor $\mathrm{E}$ and $\angle$ conlonmers of NKX-2677 calculated at B.S YP/6-31G(d).

racter (Fig. 3b). thus decreasing molecular stability:

The geometries of the stable conformers of NKX-2677, based on the PES scan were E-0, E-180, Z-0, and Z-180; where E-180 was the most stable conformation which also has the shortest $\mathrm{C}+\mathrm{C} 6$ bond length indicating a more efficient electron delocalization bewcen thiophene and cyanoacry lic acid moieties. The E configurational conformers were found to be more energetically stable by $3 \cdots+\mathrm{kcal} / \mathrm{mol}$ than the $\mathrm{Z}$ configuration. The differences in energies can be related with the $\mathrm{C}+\mathrm{C} 6$ bond length where the $\mathrm{E}$ conformers were shorter by $0.1 \cdots 0.2 \mathrm{pm}$ than the $Z$ conformers. These suggest. as pointed out previously. that the shortening of $\mathrm{C} 4-\mathrm{C} 6$ bond length indicates a more efficient $\pi$ conjugation between the thiophene and cyanoacry lic acid.

The differences between the conformers with the same configuration were mainly dependent on steric lindrance effects. As show n in Fig. 4. a decrease in atomic distance between adjacent atoms in space resulted in an increase in energ: The difference between E-() and Z-180 conformers. where the latter has a larger atomic distance but with a higher energy. could be the result of an electrostatic repulsion between sulfur and oxygen atoms. The $S \cdots O$ distance of the $Z-180$ confonmer was smaller by $60 \mathrm{pm}$ than the sum of the van der Waals radii of sulfur and oxygen atoms (3.32 pun). Based on a previous study involving intramolecular sulfur-oxygen interactions. the higher level of theory (MP2/6-3l + G(d. p)) supports a substantial electrostatic repulsion between these atoms. ${ }^{23}$

Based on the results of the PES scant. the E conformers of 


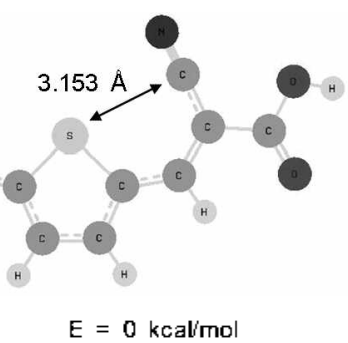

E-180
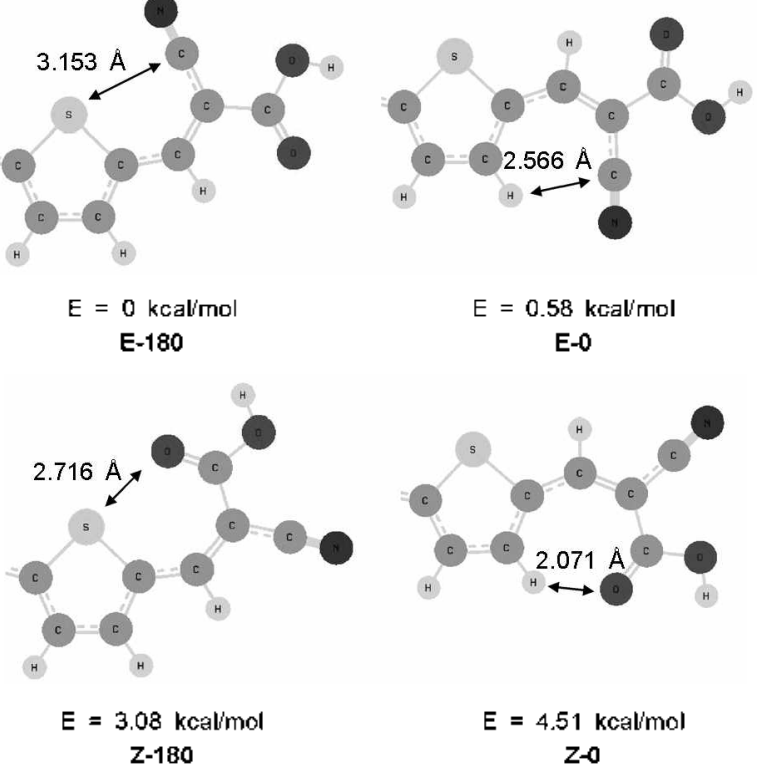

$E=4.51 \mathrm{kcal} / \mathrm{mol}$ $\mathrm{Z}-0$

Figure 4. Selected atomic distances and relative energies of $L$ and $Z$ confonmers of the ICA portion of NKX-2677 Irom tha PLS seem.

(a)

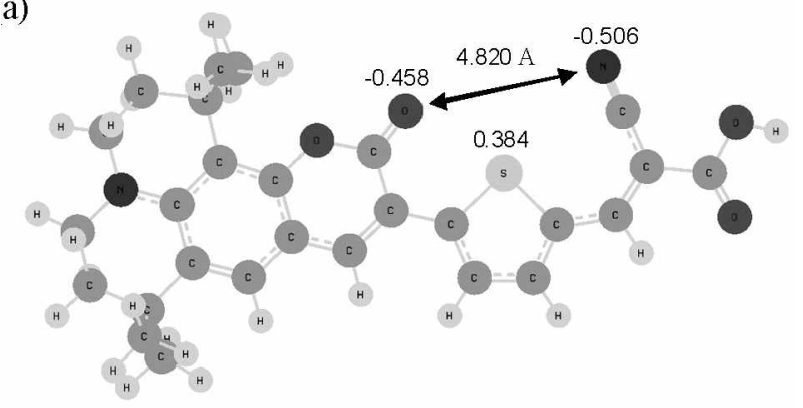

(b)

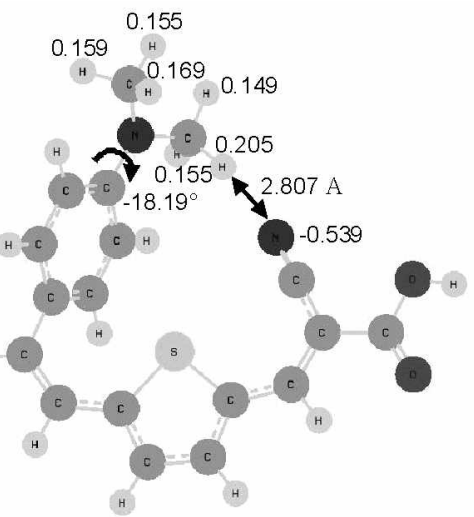

Figure 5. Selocked geometric paramelers and Mulliken charges of the ground state structure of the Li-180 conformer of (a) NKX-2587 and (b) NKX-2600

selected DSSC sensilizers containing TCA (Fig. 1) were optimized in vacue without fixed coordinales or symmetry constraints using B.3LYP/6-31G(d) level of theory. As shown in Table 1. most of the analogues were consistent with the stable conformation (E-180) derived from the PES scan of NKX-2677. For NKX-2587, 1he ligher energy of E-180 conformer was duc to the close proximity of the oxygen of the carbonyl group of
Talsle 1. Relative energies ( $\mathrm{kcal} / \mathrm{mol})$ and dihedral angle, $\theta$ (C.3-C4C6-C7), of the ground state geometry of the F contomets of analogues containing $\mathrm{lCA}$

\begin{tabular}{|c|c|c|c|}
\hline Analogue & Conformer & $\theta$ (degrees) & $\begin{array}{l}\text { Relative energy } \\
\text { (kcal } / \text { mol })^{\prime \prime}\end{array}$ \\
\hline \multirow{2}{*}{$N K X-2677$} & $\mathrm{~F}-\mathrm{-0}$ & 0.06 & 0.72 \\
\hline & F- -180 & 179.95 & 0 \\
\hline \multirow{2}{*}{ NKX-2587 } & $L-0$ & 0.02 & 0 \\
\hline & $\mathrm{F}-180$ & 179.99 & 1.14 \\
\hline \multirow{2}{*}{ NKX-2600 } & $\mathrm{E}-0$ & 0.92 & 0.90 \\
\hline & $\mathrm{L}-180$ & 175.68 & 0 \\
\hline \multirow{2}{*}{ Ll } & $\mathrm{L}-0$ & 1.05 & 0.42 \\
\hline & $\mathrm{L}-180$ & 179.26 & 0 \\
\hline
\end{tabular}

"7ero-point corrected energies.

the coumarin and the rutrogen of the cyanide group in cyanoacry lic acid which bave the same sign in Mulliken charges resulting in an electrostatic repulsion (Fig. 5a). The repulsion callsed the $\mathrm{C} 4-\mathrm{C} 6-\mathrm{C} 7$ and $\mathrm{C} 6-\mathrm{C} 7-\mathrm{C} 8$ bond angles of NKX-2587 to be slightly increased as compared to NKX-2677 and L1 analogues. This was further confinned when we replaced the oxyger of the carbonyl group of the coumarin with lydrogen and found that the stable conformation of the modified NKX2587 was E- 180 which now has a similar stable conformation with the other analogues considered in this study. I1 was also observed from Table $\mathrm{l}$ that the differences in energies of NKX2677 and LI were based on the deviation of planarity between the thiophene and cyanoacrylic acid. As in the case of NKX2600 . despite a greater deviation from planarity $\left(\sim 4^{\circ}\right)$. the lower energy of E-180 was due to the presence of a weak hydrogen bond ${ }^{24}$ between the hydrogen of the methyl group of the amine and the nitrogen of the cyanoacn lic acid. Structural evidences of the presence of the weak H-bond are the increase in the diliedral angle of the amine nearest to the cyano group by $\mathrm{ca} .11^{\circ}$ to form the $\mathrm{C}-\mathrm{H} \cdots \mathrm{N}$ bond and the increase in the Mulliken clarge of the hydrogen participating in the weak $\mathrm{H}$-bond as compared to the to the other lydrogens of the metlyl group (Fig. 5b).

The role of electronic delocalization can be quantitatively assessed by using the NBO deletion procedure. The resulting natural Lewis struclure wave function is perfectly localized. with all Lewis-type NBOs doubly occupied. By the variational principle. the Lewis-type wave function has an energy $\left(\mathrm{E}_{\text {Lewis }}\right)$ that is higher than the total elcelronic cnergy $\left(E_{\text {elec }}\right)$. As slown in Table 2. the net energy difference $\left(E_{\text {elke }}-E_{\text {Lewl }}\right.$ ) gives the energy of the delocalizing electron ( $\mathrm{E}_{\text {itelex }}$ ). For analogues NKX2677. NKX-2600. and Ll: the $\mathrm{E}_{\text {lvclox }}$ contribution favors the E-180 conformer. howerer the $\mathrm{E}_{\text {tewis }}$ strongly favors the $\mathrm{E}-\mathrm{0}$ conforner by almosi similar amount. leading to very small difference of about $\mathrm{l} \mathrm{kcal} / \mathrm{mol}$ in total energies. A reverse observation was observed for $\mathrm{NKX}-2587$, where the $\mathrm{E}-0$ conformer has a stronger $\mathrm{E}_{\mathrm{j} s \mathrm{w} w}$ than $\mathrm{E}-180$. Thus, the stability of the conformers was mainly altributed to the electronic delocalization energy which was consistent with the slortering of the $\mathrm{C} 4-\mathrm{C} 6$ bond. The extra $\pi$-bonding between $\mathrm{C} 4$ and $\mathrm{C} 6$ provides enough cxtra stabilization to overcome the destabilizing cclipsing inter- 
Table 2. Summary of the NBO analysis of the analogues containing TCA. Energies are in the unit of keal $/ \mathrm{mol}$

\begin{tabular}{|c|c|c|c|c|c|c|}
\hline \multirow{2}{*}{\multicolumn{2}{|c|}{ Confonmer }} & \multirow{2}{*}{$E_{\text {elec }}$} & \multirow{2}{*}{$\mathrm{E}_{\text {Lewis }}$} & \multirow{2}{*}{$\mathrm{E}_{\mathrm{de}] \mathrm{CC}}$} & \multicolumn{2}{|c|}{ 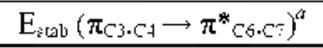 } \\
\hline & & & & & $\mathrm{NBO}_{\mathrm{del}}{ }^{b}$ & $\mathrm{NBO}_{\text {tul }} \mathrm{c}^{\mathrm{C}}$ \\
\hline \multirow{3}{*}{ NKX-2677 } & $\mathrm{E}-0$ & -1509133.04 & -1490938.38 & $-18194,66$ & 23.77 & 23.77 \\
\hline & E- 180 & -1509133.63 & -1490937.57 & -18196.07 & 26.13 & 26.13 \\
\hline & $\Delta_{(\mathrm{E} \cdot 180) \cdot \cdot \mathrm{E} \cdot 0 !}$ & 0.59 & -0.82 & 1.41 & & 2.36 \\
\hline \multirow{3}{*}{ NKX-2587 } & $\mathrm{E}-0$ & -1162863.93 & -1144738.05 & -18125.88 & 1.26 & 1.26 \\
\hline & E- 180 & -1162862.58 & -1144782.31 & -18080.27 & 2.79 & 2.79 \\
\hline & $\Delta_{(\mathrm{E}-181)-(\mathrm{E}-0)}$ & -1.35 & 44.26 & -45.61 & & 1.53 \\
\hline \multirow{3}{*}{ NKX-2600 } & $\mathrm{E}-0$ & -1078485.13 & -1076540.12 & -1945.01 & 24.66 & 24.66 \\
\hline & E-180 & -1078486.21 & -1076534.32 & -1951.89 & 27.59 & 2.82 \\
\hline & $\Delta_{\text {E. } \cdot 180) \cdot\left[\mathrm{E} \cdot 0_{1}\right.}$ & 1.08 & -5.80 & 6.88 & & -21.84 \\
\hline \multirow{3}{*}{$\mathrm{Ll}$} & $\mathrm{E}-0$ & -1041498.31 & -1039509.68 & -1988.63 & 23.45 & 23.45 \\
\hline & E- 180 & -1041498.03 & -1039513.16 & -1984.87 & 2.67 & 25.77 \\
\hline & $\Delta_{(\mathrm{E}-181)-(\mathrm{E}-0)}$ & 0.28 & -3.48 & 3.76 & & 2.32 \\
\hline
\end{tabular}

${ }^{a}$ Stabilization energy. $E_{\text {sta }}$ calculated using the ${ }^{\mathrm{t}} \mathrm{NBO}$ deletion and ${ }^{\mathrm{F}} \mathrm{Full}$ NBO procedures.

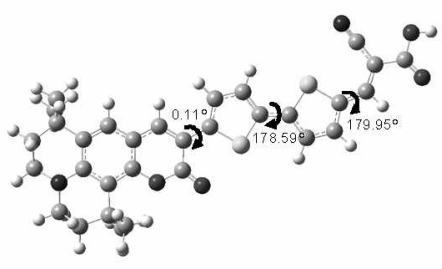

NKX-2677

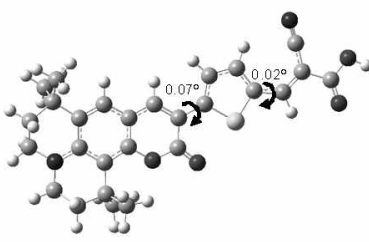

NKX-2587

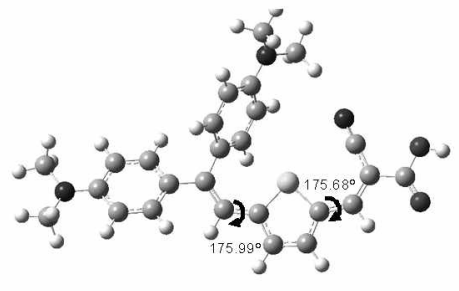

NKX-2600

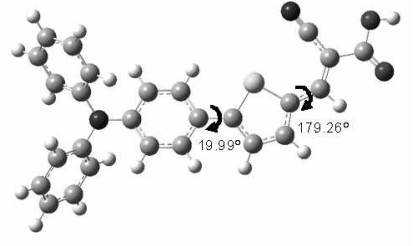

L1

Figure 6. Ground state geometries of the most stable confonmers of analogues containing TCA calculated at B3LYP/6-31G(d). Selected dihedral angles are based on adjacent ethvlene moieties.

actions that occur in the planar confonnation. The NBO analysis between the E conformers at B3LYP/6-31G(d) level shows that the E-180 conformer has a higher stabilization energy in $\pi_{\Gamma 3.54} \rightarrow \pi^{*}(c 6, c$ interaction by $c a .2 \mathrm{kcal} / \mathrm{mol}$ compared to the E-0 conformer of NKX-2677 and L1 (Table 2). The interaction was best exemplified in $\mathrm{Ll}$ analogie. where there was no influence from neighboring groups on the electron delocalization of TCA. When using the NBO deletion procedure. there was a drastic decrease in its stabilization energy of E- 180 conformer indicating that the stabilization energy was based on the delocalizaton of electrons. The NBO analy sis for the other interactions was also considered but the contributions to the E- 180 conformational stabilization were relatively small compared to the $\pi_{\square 3-\Gamma 4} \rightarrow \pi^{*}[6, c]$ electron delocalization. For NKX-2600, the weak lyydrogen bond of the E-180 conformer was exhibited by $\mathrm{n}_{\mathrm{NP}} \rightarrow \sigma^{*} \mathrm{CH}_{\mathrm{C} \text { (methyl. }}$. This was the major stabilizing factor responsible for the lower energy in NKX-2600. As shown in Table 2. an increase in the stabilization energy of $\pi_{\mathrm{r} 3 \mathrm{CA} 4} \rightarrow \pi^{*} \mathrm{Cbc}$ interaction of the E-180 conformer of NKX-2600 was observed indicating a minimal effect of the electron delocalization on the conformational energy. The ground state stnictures of the most stable conformer of NKX-2677. NKX-2587, NKX-2600. and Ll are shown in Fig. 6.

Fig. 7 shows the energy profile of the $\mathrm{E}$ conformers of the different analogues containing TCA which were calculated using B3LYP/6-31G(d) in vacto. It was observed that. for all analogues considered, there was an increase in energy levels going from $\mathrm{E}-0$ to $\mathrm{E}-180$ confonner. This can be clearly observed in NKX-2677 where an increase of up to $0.05 \mathrm{eV}$ was observed in HOMO. while in LUMO. there was a larger variation of up to $0.24 \mathrm{eV}$. The higher variation of the LUMO energy levels especially at LUMO + 5 was caused by an increase in the molecular orbital (MO) contribution of the cyanoacry lic acid due to the increase in electron delocalization of the stable conformer (Table 3). A slight widening of the band gap was observed for most of the analogues except NKX-2600 going from E-0 to E- 180 confonmer. The narrowing of band gap observed in NKX2600 was due to the stabilization energy brought about by the weak hydrogen bond in the E-180 conformer.

The excited states of the $\mathrm{E}$ conformers of the different analogues were calculated using TD-BL3YP/6-3lG(d). The vertical excitation energies for the 5 lowest singlet excited states of the $E$ conformers are shown in Table 4 . There were blue-shifting of the excitation energies going from $\mathrm{E}-0$ to E-180 conformer for NKX-2677. NKX-2587, and LI: however, a red-shift in its excitation energy was observed for NKX-2600 which was consistent with the trend in its band gap shown in Fig. 7. Though the excitation energies were almost similar to each other. the oscillator strengths vary significantly with conformation especially for analogue NKX-2600. The stability caused by the weak hydrogen bond in E-180 conformer of NKX-2600 resulted in the change in its highest oscillator strength to the second transition. This emphasizes the inportance of using the correct conformation in the theoretical calculation for electronic properties. 

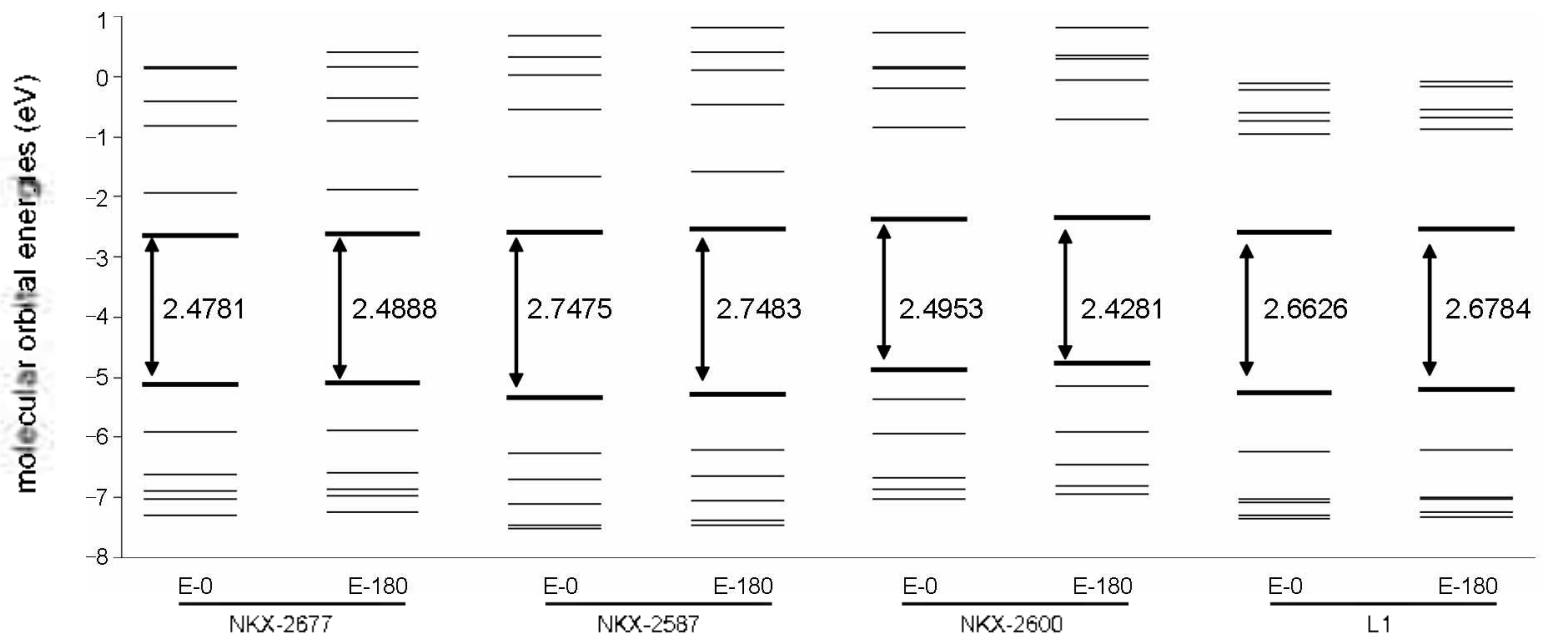

Figure 7. Molecular orbital energy levels (eV) of the E contonners of difterent analogues containing TCA moiety calculated at B3LYP/6-31 G(d) in vacio.

Table 3. Molecular orbital contribution (\%) of the 6 highest occupied and 6 lowest unoccupied molecular orbitals of NKX-2677 calculated using B3LYP/6-3IG(d) in vacto

\begin{tabular}{|c|c|c|c|c|c|c|c|c|}
\hline \multirow{2}{*}{$\mathrm{MO}$} & \multicolumn{2}{|c|}{ counzarin } & \multicolumn{2}{|c|}{ thiophene- ${ }^{a}$} & \multicolumn{2}{|c|}{ thiophene- $2^{\prime \prime}$} & \multicolumn{2}{|c|}{ cyanoacrylic acid } \\
\hline & E-0 & E-180 & $E-0$ & E- 180 & $\mathrm{E}-0$ & $E-180$ & E-0 & $E-180$ \\
\hline $\mathrm{LUMO}+5$ & 0.35 & 0.36 & 5.65 & 6.84 & 82.25 & 73.17 & 11.76 & 19.63 \\
\hline $\mathrm{LUMO}+4$ & 94.78 & 95.39 & 1.30 & 1.12 & 2.97 & 2.41 & 0.95 & 1.08 \\
\hline LUMO + 3 & 87.10 & 83.77 & 4.54 & 6.13 & 5.70 & 6.42 & 2.66 & 3.68 \\
\hline LUMO + 2 & 34.18 & 38.87 & 29.79 & 29.19 & 21.69 & 18.13 & 14.34 & 13.81 \\
\hline LUMO + 1 & 64.76 & 64.93 & 11.98 & 11.53 & 9.16 & 9.59 & 14,09 & 13.95 \\
\hline LUMO & 17.80 & 19.23 & 17.77 & 18.40 & 30.99 & 30.53 & 33.44 & 31.84 \\
\hline HOMO & 51.67 & 51.04 & 25.53 & 25.76 & 14.64 & 14.59 & 8.17 & 8.61 \\
\hline HOMO - 1 & 54.10 & 54.62 & 11.68 & 11.40 & 20.42 & 19.94 & 13.80 & 14.04 \\
\hline HOMO - 2 & 97.01 & 96.88 & 1.09 & 1.20 & 0.84 & 0.83 & 1.06 & 1.09 \\
\hline $\mathrm{HOMO}-\hat{3}$ & 31.37 & 30.94 & 23.92 & 24.55 & 18.89 & 19.37 & 25.82 & 25.15 \\
\hline HOMO - 4 & 3.10 & 3.47 & 84.03 & 82.27 & 11.80 & 12.67 & 1.07 & 1.58 \\
\hline $\mathrm{HOMO}-5$ & 0.89 & 0.57 & 13.34 & 14.55 & 85.50 & 84.23 & 008 & 0.65 \\
\hline
\end{tabular}

"Thiophene-l is the thiophene located near the commarin while thiophene-2 is near cyanoacrylic acid.

Table 4. Vertical excitation energies (mn) and oscillator strengths (in parenthesis) for the 5 lowest singlet excited states of the E confonmers of analogues containing TCA using TD-B3LYP/6-31G(d)/B3LYP/6-3IG(d) in vacto

\begin{tabular}{|c|c|c|c|c|c|c|c|c|}
\hline \multirow{2}{*}{ State } & \multicolumn{2}{|c|}{ NKX-2677 } & \multicolumn{2}{|c|}{ NKX-2587 } & \multicolumn{2}{|c|}{ NKX-2600 } & \multicolumn{2}{|c|}{$\mathrm{Ll}$} \\
\hline & E-0 & E-180 & $E-0$ & E- 180 & $E-0$ & E- 180 & $\mathrm{E}-0$ & $E-180$ \\
\hline 1 & $\begin{array}{c}537.48 \\
(1.53844)\end{array}$ & $\begin{array}{c}534.74 \\
(1.5197)\end{array}$ & $\begin{array}{c}476.65 \\
(1.2669)\end{array}$ & $\begin{array}{c}476.38 \\
(1.3418)\end{array}$ & $\begin{array}{c}541.33 \\
(0.6531)\end{array}$ & $\begin{array}{c}590.17 \\
(0.2344)\end{array}$ & $\begin{array}{c}508.36 \\
(0.7761)\end{array}$ & $\begin{array}{c}505.42 \\
(0.7310)\end{array}$ \\
\hline 2 & $\begin{array}{c}433.76 \\
(0.3280)\end{array}$ & $\begin{array}{c}432.25 \\
(0.2571)\end{array}$ & $\begin{array}{c}379.28 \\
(0.0739)\end{array}$ & $\begin{array}{c}381.53 \\
(0.0922)\end{array}$ & $\begin{array}{c}478.69 \\
(0.3566)\end{array}$ & $\begin{array}{c}495.24 \\
(0.6673)\end{array}$ & $\begin{array}{c}358.94 \\
(0.6590)\end{array}$ & $\begin{array}{c}357.91 \\
(0.5341)\end{array}$ \\
\hline 3 & $\begin{array}{c}383.57 \\
(0.0273)\end{array}$ & $\begin{array}{c}381.94 \\
(0.0302)\end{array}$ & $\begin{array}{c}35008 \\
(0.0005)\end{array}$ & $\begin{array}{c}348.34 \\
(0.0074)\end{array}$ & $\begin{array}{c}373.88 \\
(0.3155)\end{array}$ & $\begin{array}{c}377.67 \\
(0.1453)\end{array}$ & $\begin{array}{c}324.15 \\
(0.0144)\end{array}$ & $\begin{array}{c}323.52 \\
(0.0144)\end{array}$ \\
\hline 4 & $\begin{array}{c}349.18 \\
(0.0015)\end{array}$ & $\begin{array}{c}348.72 \\
(0.0006)\end{array}$ & $\begin{array}{c}339.16 \\
(0.0379)\end{array}$ & $\begin{array}{c}339.59 \\
(0.0558)\end{array}$ & $\begin{array}{c}331.71 \\
(0.0454)\end{array}$ & $\begin{array}{c}352.16 \\
(0.0149)\end{array}$ & $\begin{array}{c}317.69 \\
(0.0539)\end{array}$ & $\begin{array}{c}313.84 \\
(00755)\end{array}$ \\
\hline 5 & $\begin{array}{c}343.52 \\
(0.1124)\end{array}$ & $\begin{array}{c}341.72 \\
(0.1090)\end{array}$ & $\begin{array}{c}31065 \\
(0.0072)\end{array}$ & $\begin{array}{c}309.28 \\
(0.0191)\end{array}$ & $\begin{array}{c}326.35 \\
(0.0239)\end{array}$ & $\begin{array}{c}329.27 \\
(0.0863)\end{array}$ & $\begin{array}{c}30409 \\
(0.1456)\end{array}$ & $\begin{array}{c}304.34 \\
(0.0985)\end{array}$ \\
\hline $\operatorname{Exp}^{a}$ & \multicolumn{2}{|c|}{$511(64.3)^{b}$} & \multicolumn{2}{|c|}{$507(54.3)^{5}$} & \multicolumn{2}{|c|}{$469(30.1)^{c}$} & \multicolumn{2}{|c|}{$404(25.0)^{d}$} \\
\hline
\end{tabular}

"Values in parentheses represent molar extinction coefficients (s $\left.10^{3} \mathrm{M}^{-1} \mathrm{~cm}^{-1}\right)$. "ref. 2. "ref. 1. "ref. 3. 


\section{Conclusion}

Density functional theory and natural bond analysis were applied to investigate the molecular structure and conformational nature of 2-cyano-3-(thiophen-2-yl)acrylic acid in analogues used as sensitizers in DSSCs. Energy barriers of about $13 \mathrm{kcal} /$ mol for both $E$ and $Z$ configurations of TCA were obtained using relaxed potential energy surface (PES) scan of NKX-2677. The $Z$ conformers are of much higher energy by about $3 \sim 4$ $\mathrm{kcal} / \mathrm{mol}$ compared to the $\mathrm{E}$ conformers. It was found that the most stable conformer was E-180 having the shortest C4-C6 bond length indicating a more efficient electron delocalization. followed closely by the E-0 conformer. This trend was also observed for NKX-2600 and L1. For NKX-2587. the higher energy of E-180 over E-0 was due to the increased electrostatic repulsion between the oxygen of coumarin and the nitrogen of the cyanoacrylic acid. NBO analysis shoved that the conformational stability of the E-180 conformer was the result of the increased contribution of the electron delocalization, thereby decreasing the bond distance between the thiophene and cyanoacry lic acid for NKX-2677 and LI. In the case of NKX-2600. the major stabilization factor for the E-180 conformer was based on the presence of a weak hydrogen bonding. Based on the orbital energy level diagram. the E- 180 conformer resulted in a slightly higher energy level with a wider band gap resulting in the blue-shifting of the excitation energy of all analogues considered except for NKX-2600 due to the different stabilization factor. There was very minimal effect on the excitation energies by the change in conformation; however, there were significant variations in the oscillator strengths especially for NKX-2600.

\section{References}

1. Hara, K: Sato, T.: Katoh, R.; Furube, A.; Yoshihara, T.: Murai, M.; Kurashige, M.; Ito, S.; Shinpo, A.; Suga, S.; Arakawa, H. Adv. Funct. 1 Later: 2005, 15, 246.

2. Hara, K.: Wang, Z. S.; Sato, T.; Furube, A.; Katoh, R.: Sugihara, H.: Dant-Ol, Y.; Kasada, C.; Shimpo, A.; Suga, S. J. Phys. Chem. $B$ 2005, 109,15476

3. Hagberg, D. P.: Marinado, T: Karlsson, K. M.: Nonomura, K.; Qin, P: Boschloo, G.; Brinck, T:; Hagfeldt, A.: Sun, L. J. Ong. Chem. 2007. 72, 9550 .

4. Justin Thomas, K. R; Hsu, Y.-C.; Lin, J. T.; Lee, K.-M.; Ho, K.-C.: Lai, C.-H.) Cheng, Y.M. Chou, P.-T. Chem, Hoter, 2008, 20,1830

5. Cai-Rong, Z: Zi-Jiang, L.: Yu-Hong, C:; Hong-Shan, C: You-Zhi, W. Li-Hua, Y. J. Mol Struct. THEOCHEM 2009, 899, 86

6. Li, Y: Liu, S: Zhao, X: Chen, M; Ma, F. J. I fol. Strict. THEOCHEM $2008,867,10$
7. Yen, Y.-S.: Hsu, Y.-C.: Lin, J. T.: Chang, C.-W.: Hsu, C.-P.: Yin, D.-T. J Phus Chem C 2008, 112, 12557.

8. Chen, R: Yang, X.; Tian, H.: Wang, X. Hagfeldt, A.: Sun, L. Chem. Mater 2007, 19, 4007 .

9. Tian, H.; Yang, X.; Chen, R.: Zhang, R.: Hagfeldt, A.; Sun, L. J. Phys Chem C 2008, 112, 11023

10. Qin, P.: Yang, X.: Chen, R.; Sun, L.: Marinado, T.: Edvinsson, T.: Boschloo, G.; Hagfeldt, A. J. Phys. Chem. C 2007, 111, 1853.

11. Wang, Z.-S.; Koumura, N.; Cui, Y.; Takahashi, M.; Sekiguchi, H.; Mori, A.; Kubo, T.; Furube, A.; Hara, K. Chem. Hoter 2008 , 20,3993 .

12. Choi, H.; Baik, C.; Kang, S. O.; Ko, J.; Kang, M.-S.; Nazeeruddir, M. K.; Grätzel, M. Angen: Chent. Int. Ed. 2008, t7, 327.

13. Li, Z; Zhao, Y; Zhou, J; Shen, Y. Eur Polwn. J. 2000, 36, 2417.

14. Breitung, E. M.; Shu, C.-F; McMahon, R. T. J. Am. Chem. Soc. $2000,122,1154$

15. Wang, Q.: Camptell, W. M.: Bonfantani, E. E.: Jolley, K. W.; Ofticer, D. L.; Walsh, P. I.; Gordon, K.; Humphry-Baker, R.; Nazeernddin, M. K.: Grätzel, M. J. Phys. Chem. B 2005, 109 . 15397.

16. Ooyama, Y.: Shimada, Y.: Kagawa, Y: Yamada, Y.; Imae, I.; Komaguchi, K.: Harima, Y. Tetrahedron Lett. 2007, $48,9167$.

17. Xul, M; Wenger, S.: Bala, H.; Shi, D.; Li, R.: Zhou, Y.: Zakeenddin, S. M.: Grătzel, M.; Wang, P. J. Phus Chem C 2009, 113, 2966.

18. Frisch, M. J.; Trucks, G. W.; Schlegel, H. B; Scuseria, G. E.; Robb, M. A.; Cheeseman, J. R.; Montgomery, J. A. J.; Vreven, T.; Kudin, K. N.; Tomasi, T, Barone, V; Menuucci, B.; Cossi, M.; Scalmani, G.; Rega, N.: Pettersson, G. A.; Nakatsuji, H.; Hada, M.; Ehara, M.; Toyota, K.; Fukuda, R.; Hasegawa, J.; Ishida, M.; Nakajima, T; Honda, Y.; Kitao, O; Nakai, H.; Klene, M; Li, X:; Knox, T. E; Hratchian, H. P.; Cross, T. B.; Bakken, V: Adamo, C.; Taramillo, J.; Gomperts, R.; Stratmann, R. E.; Yazyev, O; Austin, A. I.; Cammi, R.; Pomelli, C.; Ochterski, J. W.: Ayala, P. Y.: Morokuma, K.; Voth, G. A.: Salvador, P.; Dannenberg, J. I.; Zakrzewski, V. G.; Dapprich, S.; Daniels, A. D.; Strán, M. C.; Farkas, O.: Malick, D. K.: Rabuck, A. D.: Raghavachari, K.; Foresman, I. B.; Ortiz, I. V.: Cui, Q.; Baboul, A. G.; Clifford, S.: Cioslowski, T.; Stefanov, B. B.; Lin, G.: Liashenko, A.; Piskorz, P.: Komaromi, I.: Martin, R. L.: Fox, D. L.; Keith, T.: Al-Laham, M. A.; Peng, C. Y.: Nanayakkara, A.: Challocombe, M.: Gill, P. M. W. Jolunson, B; Chen, W: Wong, M W.; Gonzalez, C.; Pople, J. A., Gatusian 03 Rerision D. 01; Gaussian, Inc.: Wallingford CT, 2004.

19. Becke, A. D. J. Chent. Phys. 1993, 98, 5648.

20. Lee, C; Yang, W; Parr, R. G. Phys. Rev: $B$ 1988, $37,785$.

21. Glendening, E. D; Badenhoop, J. K; Reed, A. E.; Carpenter, T. E.; Weinhold, F., NBO Version 3.1, Theoretical Chemistry Institute, University of Wisconsin, Madison, USA.

22. Tenderholt A. L., QMForge, version 2. 1, Standford University, Standford, CA, USA, October 30,2007 , http//qmforge solreforge. net.

23. Markham, G. D.; Bock, C. W. J. Hol. Snnct.:THEOCHEM 1997. 418.139.

24. Desiraju, G. R.; Steiner, T. The Heak Hydrogen Bond in Structual Chemistry and Biologv; Oxford University Press: Oxford, New York, 1999 